\title{
Mehmed Âkif'in Kendi Resimlerinde Gördüğü: Sûretten Sîrete
}

\author{
Mustafa Sefa ÇAKIR*
}

\begin{abstract}
Öz
İnsanın, nisyanla malul olması gibi nisyana karşı kimi çözüm arayışları da malumdur. Bu çözümlerden biri de fotoğraflardır. Eskilerin daha ziyade resim olarak ifade ettiği fotoğraflar donmuş hatıralar hâlinde kısmi bir kalııılığa sahiptir. Akıp giden zamana ve unutulan günlere küçük parantezler açan fotoğrafların bazıları, şairlerin elinde bir de şiirle süslenerek daha etkili bir hüviyette karşımıza çıkmaktadır. Fotoğraflarının arkasına şiir yazarak dostlarına ve yakınlarına gönderen şairlerden biri de Mehmed Âkif'tir. Bu manzumelerde şair daha ziyade kendisiyle ilgili izlenimlerinden bahsetmiştir. Fotoğrafına bakan şairin gördüğü sûretinin yanında yaşadıklarının ve hatta karakterinin izlerini de görmesi, bunları işlemesi doğaldır. Bu çalışmada fotoğraf arkası şiirlerinden yola çıkarak Âkif'in kendi dilinden, kendi ile ilgili izlenim ve düşünceleri gözler önüne serilecektir. Bu noktada faniliği çokça vurgulayan ve özellikle son yıllarında kaleme aldığı manzumelerinde kendisiyle ilgili ümitsizliğin ağır bastı̆̆ görülen Âkif’te derin bir hüzne şahitlik edilmektedir. Fotoğraflarında simasıyla bile insana çok şey anlatan Âkif'in fotoğraflarının arkasında kendini anlattı̆̆ şiirleri de hususi bir öneme sahiptir.
\end{abstract}

Anahtar Kelimeler: Âkif, resim, fotoğraf, sûret, sîret.

* Dr. Öğr. Üyesi, Sivas Cumhuriyet Üniversitesi Edebiyat Fakültesi, Sivas, Türkiye.

Elmek: mscakir@cumhuriyet.edu.tr

http://orcid.org/0000-0002-5159-7340.

Geliş Tarihi / Received Date: 19.09.2021

Kabul Tarihi / Accepted Date: 20.11.2021 


\title{
What Mehmed Akif Sees in His Own Photos: From Appearance to Life
}

\begin{abstract}
It is known that people are forgetful, as well as seeking solutions to forgetfulness. One of these solutions is photos. Photographs, which the ancients refer to as paintings, have a partial permanence as frozen memories. Some of the photographs, which open small brackets to the passing time and forgotten days, appear in a more effective way by being decorated with a poem in the hands of the poets. One of the poets who wrote poems on the back of his photographs and sent them to his friends and relatives is Mehmed Akif. In these poems, the poet mostly talked about his impressions about himself. It is natural for the poet looking at his photograph to see and process the traces of his experiences and even his character, as well as the outward appearance he sees. In this study, based on the poems behind the photography, Akif's impressions and thoughts about himself will be revealed in his own language. At this point, a deep sadness is witnessed in Âkif, who emphasizes mortality a lot and it is seen that despair about himself predominates, especially in his poems that he wrote in his last years. Telling a lot to people even with his face in his photographs, Âkif's poems in which he tells about himself behind his photographs also have a special importance.
\end{abstract}

Keywords: Akif, painting, photography, appearance, life. 


\section{Giriş}

Mehmed Âkif, benliğini hakikatleri uğruna feda eden hatta âdeta "fenâ fi'l-da'vâ” derecesine ulaşan müstesna şairlerimizden ve fikir öncülerimizdendir. Yakın zamanlarda vefat eden Sezai Karakoç da aynı çizginin günümüze ulaşan temsilcisiydi. Dikkat edilirse bu gibi insanların bir ortak noktası da fazla fotoğraflarının olmamasıdır. Mevcut fotoğrafları oldukça sınırlı sayıdadır, sürekli aynı kareler döner durur.

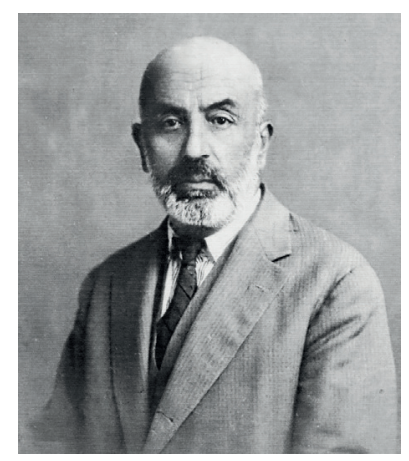

Âkif in fotoğraflarına bakıldığında ilk göze çarpan derin bir hüzündür. Belki bir iki istisna hariç gülen, gülümseyen fotoğrafı yoktur. Yılların ve yaşananların getirdiği yorgunluk hemen fark edilir. Ancak bu yorgunluk ve çekilen çileler (çile demişken Necip Fazılıın yaşlılık zamanlarında çekilen, yüzü kırış kırış olmuş ama hâlâ bir şeyler anlatan, bir mücadeleye çağıran fotoğrafı da akla gelebilir) bir bezginlik değil aksine sürekli gayret gösterme heyecanını taşıyan bir vasıftadır.

Mehmed Âkif`in Dârülfünûn'daki öğrencilerinden Reşat Nuri Güntekin, onun gözlerindeki ateşi görmüş ve son demlerindeki hasta hâlinde çekindiği fotoğraflarda bile bunun aşikâr olduğunu ifade etmiştir: 


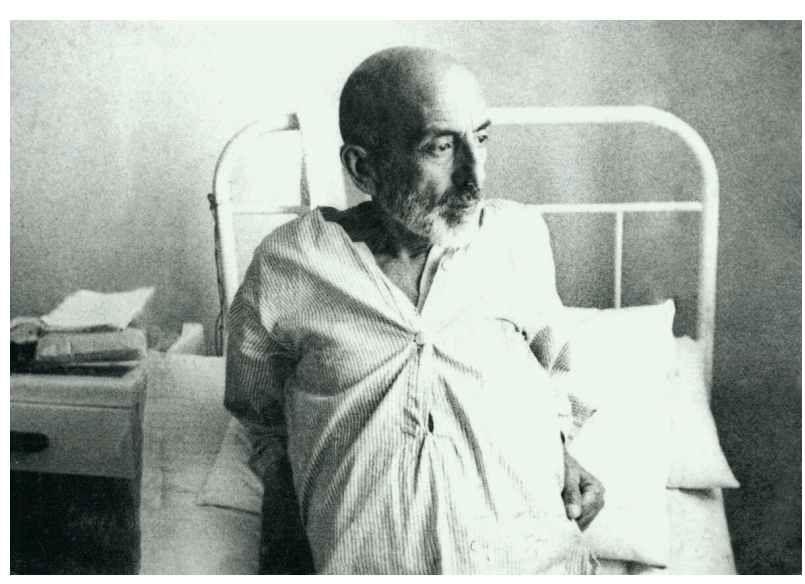

“Âkif'in son günlerinde hasta yatağında çekilmiş resmine bilmem dikkat ettiniz mi? Harâbe hâlindeki çehrenin gözlerinde o kadar harikulâde bir ateş ve nûr güzelliği vardı ki insana âdeta şairin ruhun ebediliği hakkındaki kanaatini kabul ettirecek gibi olur.» (Edib, 2011: 733)

İnsanlar unutulmamak arzusuyla olsa gerek başkalarına zaman zaman fotoğraflarından hediye etmişlerdir. Şairler ise hediye edilen bu fotoğrafların arkasına veya üzerine kimi zaman şiir de eklemişler ve duygularını ifade etmişlerdir. (Aydoğan, 2006: 43) Peki, Âkif kendi fotoğraflarına baktığı zaman ne görmüştür ve neler ifade etmiştir? Bunu Safahat'ına aldığı ve "Resmim İçin" gibi başlıklandırdığı şiirlerinde ve yine Safahat'ında bulunmayan ama yakınlarına söz konusu fotoğrafları gönderdiğinde arkasına yazdığı mısralarda görebilmekteyiz.

\section{Âkif in Fotoğraf Arkası Şiirleri}

$\mathrm{Bu}$ şiirlerden ilki önce Sıratımüstakim dergisinde yayımlanan ve sonra Safahat'a da alınan “Bir Resmin Arkasına Yazılmış İdi” başlıklı şiirdir. Şiir şu şekildedir: 
"Kiminin yâd-1 ihtirâmı kalır,

Kendi gittikte câ-nişîni olur;

Kiminin bir yı̆̆ın meberrât1,

Toplanır, heykel-i metîni olur;

Kiminin de olanca hâtırası,

Böyle bir sâye-i hazîni olur!” (Ersoy, 2017: 117)

Gölgesinde bile hüzün görüyor şair: "sâye-i hazîn"... Kiminin saygıyla anılan bir hatırası, kiminin arkasında sağlam bir anıt olarak bırakacağı iyilikleri kalırken Âkif de bırakacağı yegâne hatıranın hüzünlü bir gölge olacağını kendisi için düşünüyor.

Biri “Resim İçin” diğerleri “Resmim İçin” başlıklı dört şiir de Safahat'ın Gölgeler kitabında yer almaktadır. Şiirler şu şekildedir:

"Toprakta gezen gölgeme toprak çekilince,

Günler şu heyûlâyı da er, geç silecektir.

Rahmetle anılmak, ebediyyet budur amma,

Sessiz yaşadım, kim beni, nerden bilecektir?” (Ersoy, 2017: 450)

Âkif'in kendisiyle ilgili en meşhur mısralarından birisi belki de budur; “Sessiz yaşadım, kim beni, nerden bilecektir?”. Gerçekten öyle midir? Gördükleri, yaşadıkları karşısında göğsünün bir volkan gibi kaynadığını bildiğimiz Âkif, evet, zâhiren susmuş, kendini gönüllü bir sürgüne dahi mahkûm etmiştir ancak bu sessiz yaşadığı anlamına mı gelmektedir? Âkif, dün de bugün de en gür sesiyle hâlâ bize seslenmekte değil midir? Bugün her bir hatip, konuşmasında Âkif'e müracaat etmek zaruretini kendinde görmekte değil midir? Değil midir Âkif, bizim sesimizle, bizim nefesimizle sınıflarda, amfilerde, kürsülerde, meydanlarda sayılamayacak çok insana seslenen?

Âkif'in cismani bedeni aramızdan ayrılmıştır. Ama güçlü her şair gibi manevi bünyesiyle hâlen aramızdadır. Rahmetle anılmaktadır ve kendisinin de ifade ettiği üzere ebediyyet budur. 
"Bir canlı izin varsa şu toprakta, silinmez;

Ölsen, seni sırtında taşır toprağın altı.

Ey gölgeden ümmîd-i vefâ eyleyen insan!

Kaç gün seni hatırlayacaktır şu karaltı?” (Ersoy, 2017:450)

“Ölsen, seni sırtında taşır toprağın altı” mısraıyla teşhis sanatının harikulâde örneklerinden birini ortaya koyan Âkif, burada da gölge metaforunu kullanmıştır. Başka insanlardan vefa ümidini kesen şair, bu ümidini gölgesine bağlamıştır ancak onun da bunu fazla sürdüremeyeceğini, ölmesiyle son bulacağını bilmektedir. Gölgesinin kaç gün daha hatırlayacağını sorarak aslında gölgesinin kaç gün daha var olacağını kısaca dünyada sanki kaç gün daha yaşayacağını ima etmiştir.

Âkif, hayatı boyunca türlü imtihanlardan geçmiştir. Bu imtihanların belki de en zor süreci -son altı ay hariç- ömrünün son on bir yılına denk gelen Mısır yılları olsa gerektir. Orada yaşadığı yalnızlık, hasret Âkif'i daha da yormuştur. Âkif'in meselesi vefasızlık görmesi değil, vefa gösterecek dostlarının kalmamış olması yahut araya uzun mesafelerin girmesidir. Mektuplar da onun bu sızısını bir yere kadar dindirmekte, ünsiyet ihtiyacını bir miktar giderebilmektedir. Hâl böyle olunca Âkif de yer yer karamsarlığa kapılmış ve bir izinin dahi olmayacağını düşünmüştür.

"Dış yüzüm böyle ağardıkça ağarmakta, fakat,

Sormayın iç yüzümün rengini: Yüzler karası!

Beni kendimden utandırdı, hakîkat şimdi,

Bana hiç benzemeyen sûretimin manzarası!” (Ersoy, 2017: 451)

Bu mısralarda da yine derin bir hüzne şahit olmaktayız. Âkif, fotoğrafta gördüğü sûretinde saçlarının, sakallarının ağardığını iyiden iyiye görmekte buna karşın iç yüzünün rengini ise yüzler karası diye nitelemektedir. Kullandığı tezat sanatıyla söylemek istediğini daha vurgulu bir hâle getirmiş, kendini iç yüzündeki karalığa nispet edip sûretindeki eskiye nazaran daha da beyazlayan manzarayı kendine benzememekle nitelemiştir. 
Yine bir fotoğrafın arkasına yazılmış ancak Gölgeler kitabına "Çocuklara" başlı̆̆ı ile alınan şiir şu şekildedir:

"Ne odunmuş babanız: Olmadı bir baltaya sap!

Ona siz benzemeyin, sonra ateştir yolunuz.

Meşe hâlinde yaşanmaz, o zamanlar geçti;

Gelen incelmiş adam devri, hemen yontulunuz.

Ama dikkatli olun: Bir kafanız yontulacak;

Sakın aldanmayın: İncelmeye gelmez kolunuz!'(Ersoy, 2017: 452)

Bu manzume(nin ilk dört misra1) Âkif' in 1929 yılında Mahir İzıe yazdığ 1 bir mektuba koyduğu ve iki oğluyla çekindiği fotoğrafın arkasına yazılmıştır. Âkif her ne kadar kendine 'odun' diyerek haksızlık etse de yolunu ateş olarak tanımlamakta haklı. Zihnen incelmek gerektiği noktasındaki görüşünü bileğin incelmemesi gerektiğini vurgulayarak desteklemiştir.

Âkif in Safahat dışında kalan ancak Eşref Edib Bey'in yayımladığı iki şiir daha mevcuttur. Bunlardan "Resmimin Arkasına" başlı̆̆ını taşıyan şiir şu şekildedir:

"Hepsi göçmüş, hani yoldaşlarının hiçbiri yok!

Sen mi kaldın, yalnız kâfileden böyle uzak?

Postu sermekse merâmın yola, serdirmezler;

Hadi, gölgenle beraber silinip gitmene bak!" (Ersoy, 2017: 500)

Yine yalnızlığın iliklere kadar hissedildiği bu dörtlüğ̈̈n ilk iki mısraı Mısır'daki hamisi Abbas Halim Paşa'nın vefatı üzerine söylemiştir. Son dostları, yakınları, destekçileri de bir bir ahirete göçen Âkif, burada da kendisini bir an evvel bu dünyadan çekip gitmesi gereken biri olarak görmektedir.

"Resmim İçin" başlıklı diğer şiir ise şu şekildedir:

"Şu serilmiş görünen gölgeme imrenmedeyim...

Ne saâdet, hani ondan bile mahrûmum ben.

Daha bir müddet eminim bu hayatın yükünü,

Dizlerim titreyerek çekmeye mahkûmum ben.

Çöz de artık yükümün kördüğüm olmuş bağını,

Bana çok görme, İlâhî, bir avuç toprağını!...” (Ersoy, 2017: 500) 


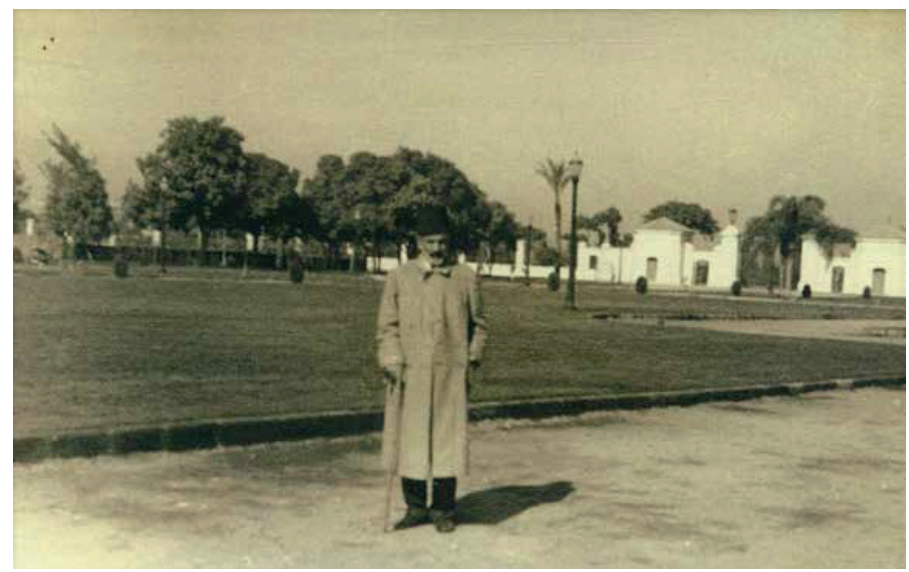

$\mathrm{Bu}$ şiiri Âkif, vefatından bir sene önce yazmıştır. O zamanlar Mısır'da özel ders verdiği Prens Aziz Hasan'ın çocuklarıyla sağlık sorunları nedeniyle ders yapamayacakları üzere konuştuktan sonra hatıra kalması için fotoğraf çekinmişlerdir. Fotoğrafta kendisini çökmüş bir vaziyette gören Âkif, hâline acımış, "Bundan bir ay evvel Merc'e gitmiştim. Merhum Prens Hasan’ın kerimeleri resmimi çıkardılar. Gölgesi yerlere serilmiş, kendisi ayakta durabilmek için asasına dayanan bu zavallı ihtiyarın hali bana dokundu." demiş ve bu mısraları kaleme almıştır. (Kahraman, 2020: 409)

Bir diğer fotoğraf arkası şiir ise yine Mısır'da ve 1926 yılında kaleme alınmıştır. Âkif’in kızı Suat doğum yapmış ve kızına “yarın” anlamına gelen "Ferda" ismini vermiştir. Doğum haberini alan Âkif, oğlu Mehmet Emin'le birlikte çektirdikleri bir fotoğrafın arkasına, torununa hitaben yazdığı şiiri ekleyerek göndermiştir. Fotoğrafin üstüne Âkif, “Ani’l gıyâb tanıdığım Ferda Hanım'a"; oğlu Mehmet Emin de, "Pek sevgili Suat ablama, kardeşiniz M. Emin" notlarını düşüyor. "Ferda Kadın” başlıklı şiir şu şekildedir:

"Ferda kadın, Ferda kadın!

Ben görmeden sevdim seni,

Sen galiba gördün beni 
Pek ihtiyar, hoşlanmadın

Ferda kadın, Ferda kadın!

Ey yavrumun yavrusu

Pek tatlı şeysin doğrusu

Lâkin neden çirkin adın?

Yok yok... Adın cidden güzel

Aydan güzel, günden güzel

Ay gün nedir? Senden güzel

Hatta derim: Benden güzel

Zira “yarın” "dün”den güzel.» (Turinay, 2021: 917)

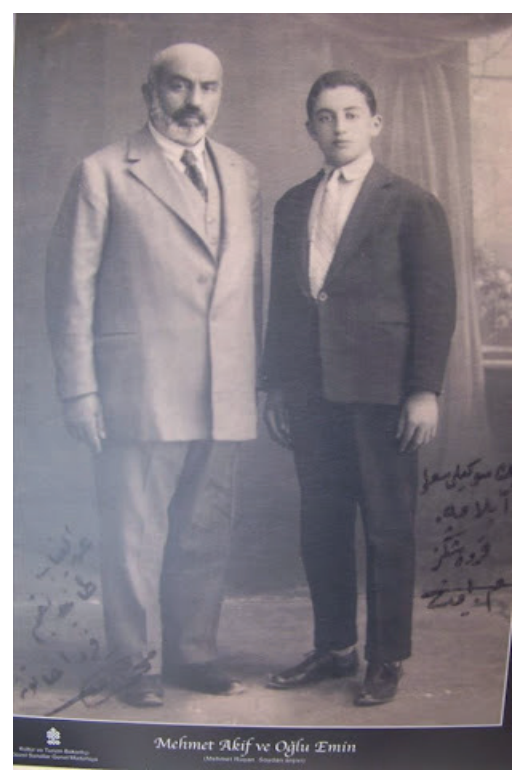

Necmettin Turinay'ın 2021 yılında TBMM yayını olarak hazırladığ külliyat içinde ilk kez yayımlanan bir başka fotoğraf arkası şiir Şerif Muhittin Targan'a gönderilmiştir. Âkif, Gölgeler'in son şiiri "Sanatkâr"1 da kendisi için önemli isimlerden biri olan Targan'a misafirperver bir tavır sergileyen Roosevelt'e ithaf etmiştir. Üzerine "Müştâkın Mehmed Âkif” notu düşülen 
fotoğrafın arkasındaki şiir şu şekildedir:

"Beni rahmetle anarsın ya, işitsen bir gün

Şu sağır kubbede hâib sesimin dindiğini?

Bu heyûlâya da bir kerrecik olsun bak ki

Ebediyyen duyayım kabrime nûr indiğini.” (Turinay, 2021: 939)

Son bir şiir de Orhan Seyfi'nin çıkardığı Ayda Bir mecmuasında, Temmuz 1936'da yayımlanan şiirdir. Dergi Âkif'in çökmüş bir fotoğrafını da koymuş ve altına şu notu eklemiştir: "Büyük vatan şairi Mehmet Akif... On yıldır ayrı kaldığı vatanına dönüp rahatsız bulunan üstadımıza sağlık dileriz." 1926'da Ferda Kadın şiirinde yarına, geleceğe olan ümit yerini ye'se bırakmıştır. Hem de bırakın su bulunmasını, serabının dahi olmadığı bir ye's. Zamanında, "Ye's öyle bataktır ki: Düşersen boğulursun./ Ümmîde sarıl sımsık1, seyret ne olursun!/ Azmiyle, ümîdiyle yaşar hep yaşayanlar" diyen şairin ömrünün son demlerinde geldiği nokta üzüntü vericidir.

"Arkamda serilmiş yere bir mazi var,

Karşımdaki müstakbelim ondan da harap.

Hâl ortada, bir çöl ki sudan vaz geçtim

Yok ye'simi aldatmaya bir damla serap.” (Turinay, 2021: 961)

\section{Sonuç}

Âkif $>$ in en etkileyici fotoğraflarından biri Mısır yıllarında, bir bankın üzerinde, ufku seyre daldığı fotoğraftır. Bu tablo ne çok şey anlatır... Mücadeleyle geçen koca bir ömür, acılar, hayal kırıklıkları, gurbet, yalnızlık... Ayağındaki ayakkabının delik deşik olması ve üzerindeki elbiselerin yıpranmışlığı maddi açıdan yaşanan sıkıntılara işaret ederken yarısı görünen yüzdeki mümin ve mutmain hâl, manevi dinginliği gösterir. Belki de yönünü Anadolu topraklarına, İstanbul'a dönmüş maziyi ve istikbâli düşünüyordu. İstiklâl için canhıraş mücadele eden, istiklâlin şiirini yazan şâir istikbâl için ne türlü kaygılar içindeydi kim bilir...

Son sözü yine Âkif söylesin. Hem bu fotoğrafla hem de bu fotoğrafin arkasına yazılmış olmasa da "El-Uksur"da başlıklı şiirden alınan bu mısralarla:

"Evet, bu sâha-i cûşun, bu cûş-i ezvâkın 
İçinde ben, yalınız ben zavallı gülmüyorum...

Oturmuş ağliyorum, ağlasam da ma'zûrum:

Vatan-cüdâ gibiyim ceddimin diyârında!

Ne toprağında şu yurdun, ne cûybârında,

Bir âşinâ sesi, yâhud bir âşinâ izi var!

Sadâma beklediğim aksi vermiyor ovalar.

Bileydim ey koca Şark, ey cihân-1 dûrâdur,

Senin nerendeki evlâdının nasîbi huzûr?

Başın belâlara girmiş; elin, kolun pâmâl,

İçinden esti ki bir gün hevâ-yı istiklâl?

Görür müyüm diye karşımda Müslüman yurdu,

Bütün diyârını gezdim, ayaklarım durdu.

Yabancı sesleri geldikçe reh-güzârımdan,

Hep inkisâr-1 emel taştı rûh-i zârımdan!

Vatan-cüdâ olayım sînesinde İslâm'ın?

Bu âkıbet, ne elîm intikâmı eyyâmın!

Benim ki yaşlıyım artık, düşük kolum, kanadım;

Bu intikâmı çalışsın da alsın evlâdım.” (Ersoy, 2017: 280)

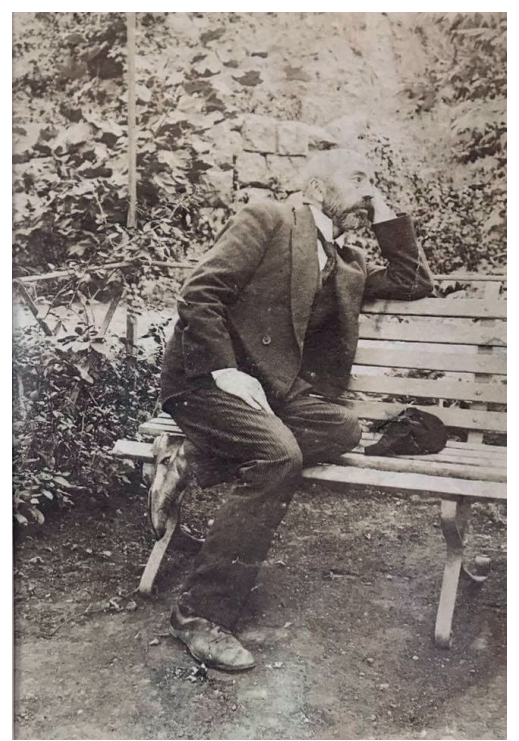




\section{Kaynakça}

Aydoğan, Bedri (2006). "Edebiyatçıların Arkası Şiirli Armağan Fotoğrafları”, Ç.Ü. Sosyal Bilimler Enstitüsü Dergisi, Cilt 15, Say1 1, s.43-68.

Edib, Eşref (2011). Mehmed Âkif: Hayatı, Eserleri ve Yetmiş Muharririn Yazıları, (hzl. Fahrettin Gün). İstanbul: Beyan Yay.

Ersoy, Mehmed Âkif (2017). Safahat, (hzl. M. Ertuğrul Düzdağ). Ankara: TDV Yay.

Kahraman, Âlim (2020). Mehmet Âkif Tutuşmuş Bir Yürek, Adanmış Bir Hayat. İstanbul: Büyüyenay Yay.

Turinay, Necmettin (2021). İstiklal Marşıının 100. Yılında Mehmet Akif Ersoy Şiir Külliyatı Safahat. TBMM Yay. 